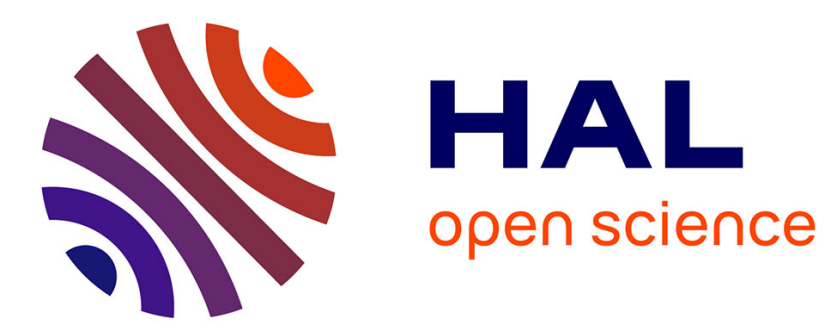

\title{
Nutrients in mode waters of the northeast Atlantic
}

Gilles Reverdin, Marina Lévy, Patrick Raimbault, Dominique Lefèvre

\section{To cite this version:}

Gilles Reverdin, Marina Lévy, Patrick Raimbault, Dominique Lefèvre. Nutrients in mode waters of the northeast Atlantic. Journal of Geophysical Research. Oceans, 2009, 114, pp.C10004. 10.1029/2009JC005546 . hal-00741486

\section{HAL Id: hal-00741486 \\ https://hal.science/hal-00741486}

Submitted on 6 Jan 2022

HAL is a multi-disciplinary open access archive for the deposit and dissemination of scientific research documents, whether they are published or not. The documents may come from teaching and research institutions in France or abroad, or from public or private research centers.
L'archive ouverte pluridisciplinaire HAL, est destinée au dépôt et à la diffusion de documents scientifiques de niveau recherche, publiés ou non, émanant des établissements d'enseignement et de recherche français ou étrangers, des laboratoires publics ou privés.

$$
\text { Copyright }
$$




\title{
Nutrients in mode waters of the northeast Atlantic
}

\author{
G. Reverdin, ${ }^{1}$ M. Lévy, ${ }^{1}$ P. Raimbault, ${ }^{2}$ and D. Lefèvre ${ }^{2}$ \\ Received 29 May 2009; accepted 17 July 2009; published 3 October 2009.
}

[1] Programme Océan Multidisciplinaire Méso Echelle (POMME) seasonal surveys in the northeast Atlantic $\left(39^{\circ} \mathrm{N}-44.5^{\circ} \mathrm{N} ; 16.5^{\circ} \mathrm{W}-20.3^{\circ} \mathrm{W}\right)$ in 2001 are used to investigate the subduction of nutrients in the subsurface mode waters. Isopycnal subsurface distributions are used to estimate inorganic nutrients at the time of late winter restratification. These nutrient concentrations were close to winter near-surface concentrations, indicating a moderate consumption of nitrate $\left(0.2-0.3 \mu \mathrm{M} \mathrm{kg}^{-1}\right)$ and dissolved inorganic carbon $\left(2-3 \mu \mathrm{M} \mathrm{kg}^{-1}\right)$ in the surface layer before the effective subduction. Spring survey nutrient concentrations on isopycnal surfaces are lower north of $41.7^{\circ} \mathrm{N}$ indicating younger waters than further south. The seasonal increase of subsurface nutrients from spring to late summer diminishes from the shallower isopycnals to the deeper ones of the mode waters. It is also larger north of $41.7^{\circ} \mathrm{N}$ than south of it with values as large as $2 \mu \mathrm{M} \mathrm{kg}^{-1}$ for nitrate and $10 \mu \mathrm{M} \mathrm{kg}^{-1}$ for inorganic carbon. This evolution is mostly attributed to remineralization processes, both from falling particles (at least 15\%) and from preformed dissolved organic matter (at most $30 \%)$. Ratios of nutrient changes to oxygen changes are often larger than Redfield ratios for nitrate (N:apparent oxygen utilization (AOU) at least 1:7) and phosphate (P:AOU at least 1:150) consistent with favored remineralization of $\mathrm{P}$ and $\mathrm{N}$ over $\mathrm{C}$, both for dissolved and particulate organic pools.

Citation: Reverdin, G., M. Lévy, P. Raimbault, and D. Lefèvre (2009), Nutrients in mode waters of the northeast Atlantic, J. Geophys. Res., 114, C10004, doi:10.1029/2009JC005546.

\section{Introduction}

[2] The midlatitude northeast Atlantic is a region were maximal winter mixed layer is often larger than $200 \mathrm{~m}$, and where the seasonal retreat of the mixed layer between winter and spring leaves a thick layer of weakly stratified water (the northeast Atlantic mode waters), that is deep enough to be isolated from light and therefore not to experience further primary production. This water which forms a large volume of mode water will be a subsurface reservoir of nutrients that is later advected across part of the North Atlantic, before been reentrained in the surface layer in obduction regions. What sets the nutrient content of such layer should therefore be investigated.

[3] Model results and sea surface chlorophyll observations in this region [Lévy et al., 2005; K. Karleskind et al., Subduction of carbon, oxygen, and nitrogen in subpolar mode waters, unpublished manuscript, 2009] suggest that the seasonal mixed layer retreat triggers the near-surface bloom, and that the mode waters formed at that time are still rich in inorganic nutrients. This contrasts with observations south of the Gulf Stream that suggest that $18^{\circ} \mathrm{C}$ North Atlantic subtropical mode waters are poor in nutrients at the time they are formed, as discussed by Palter et al. [2005]. Indeed, in this area south of the Gulf Stream, model results [Krémeur

${ }^{1}$ LOCEAN, IPSL, UPMC, CNRS, Paris, France.

${ }^{2}$ LMGEM, UMR 6117, COM, CNRS, Marseille, France.

Copyright 2009 by the American Geophysical Union. 0148-0227/09/2009JC005546 et al., 2009] suggest that the phytoplankton bloom has consumed the near surface nutrients before the complete retreat of the mixed layer and before the formation of mode water. In the northeast Atlantic, on the other hand, the winter mixed layer is often deeper than south of the Gulf Stream, and model results of Karleskind et al. (unpublished manuscript, 2009) suggest that primary production is strongly limited by light limitation before the time of subduction. Our first objective is to provide a data-based estimate of oxygen and nutrients at the time of mode water formation in the northeast Atlantic.

[4] Later subsurface evolution of inorganic nutrients and oxygen can be influenced in subsurface mode waters by two pools: the pool of organic nutrients present at the time of mixed layer retreat, and particle flux through the layer originating from further up in the water column, and to a large extent resulting from export of biomass produced in the euphotic layer. Our second objective is to estimate from data the evolution of the nutrients in the subsurface mode water during the stratified part of the year. From this quantitative analysis and estimation of Redfield ratios, we hope to get some insight on remineralization processes in these rather young mode waters.

[5] The data used here are from the Programme Océan Multidisciplinaire Méso Echelle (POMME) experiment [Mémery et al., 2005] and are distributed over a fairly wide domain (from $16^{\circ} \mathrm{W}-21^{\circ} \mathrm{W}$ and $39^{\circ} \mathrm{N}-44.5^{\circ} \mathrm{N}$ ) away from major oceanographic currents. This area was sampled at a nearly $50 \mathrm{~km}$ resolution during four 3-week-long surveys (P0, P1, P2, and P3) both physically (conductivitytemperature-depth-lowered acoustic Doppler current profiler 


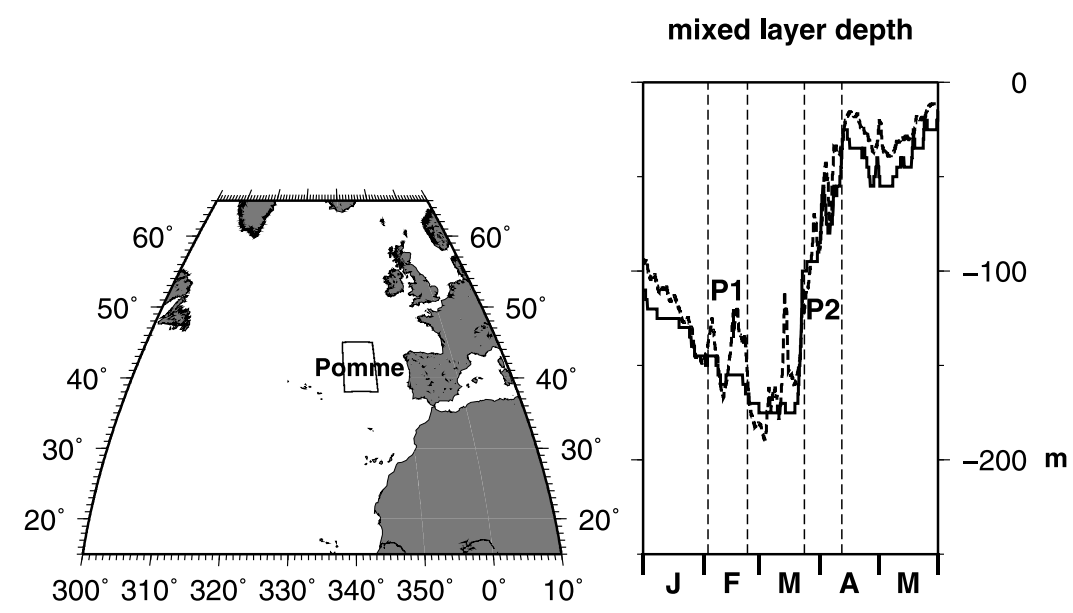

Figure 1. (left) Map indicating where the POMME surveys took place. (right) Time series of mixed layer depth estimated from a 1-D model (solid line) [Caniaux et al., 2005], as well as mean mixed layer depth over the POMME area from a diagnostic 3-D model (dashed line) [Giordani et al., 2005].

casts (CTD-LADCP)) [Reverdin et al., 2005], as well as chemically for most major inorganic nutrients [Fernández et al., 2005a; González Dávila et al., 2005], some of the organic nutrients [Sohrin and Sempéré, 2005], some of the trace nutrients [Blain et al., 2005] and in different size classes of phytoplankton [e.g., Maixandeau et al., 2005; Claustre et al., 2005]. These studies focused on primary and new production in the surface euphotic layer. The emphasis of this paper on the other hand is on the subsurface mode waters formed mostly when mixed layer retreats.

[6] Actually, we have no direct nutrient/oxygen observations right at the time of mode water formation, i.e., at the time of mixed layer retreat. Survey P1 (3-23 February 2001) took place at least two weeks before restratification started, which in most places happened in the first part of March, whereas survey P2 (24 March to 12 April 2001) took place at least two weeks after the beginning of the retreat [Caniaux et al., 2005; Gaillard et al., 2005] (Figure 1). Survey P1 witnessed some phytoplankton growth due to primary production [Claustre et al., 2005; Leblanc et al., 2005], but often to a much lesser level than during P2. There was also a partial depletion of inorganic nutrients from the surface waters between surveys P1 and P2 [Fernández et al., 2005b; González Dávila et al., 2005; Blain et al., 2005]. This brings uncertainty on what the initial conditions are at the initial time of mode water formation. This raises a methodological issue on how to make these estimations which we will also address in this paper.

\section{Data and Methods}

\subsection{Mode Water During POMME}

[7] Mode waters are the weakly stratified waters that form the bulk of the waters found at subsurface after the retreat of the mixed layer, and we will focus our investigation on this water mass. The presence of mode waters is illustrated on Figure 2 with the low stratification (large separation between isopycnal surfaces) in the $\sigma\left(\sigma=\rho_{\Theta}-\right.$ 1000 where $\rho_{\Theta}$ is the potential density) range $[26.95,27.05]$ near $42^{\circ} \mathrm{N}-43^{\circ} \mathrm{N}$ (depth range $100-300 \mathrm{~m}$ ), and in the $\sigma$ range $[26.85,26.95]$ near $40.5-41.5^{\circ} \mathrm{N}$ (depth range $100-$ $250 \mathrm{~m}$ ). This is an indication of recent formation of mode waters by mixed layer retreat. The two areas are separated by an eastward current that has regularly been found in this

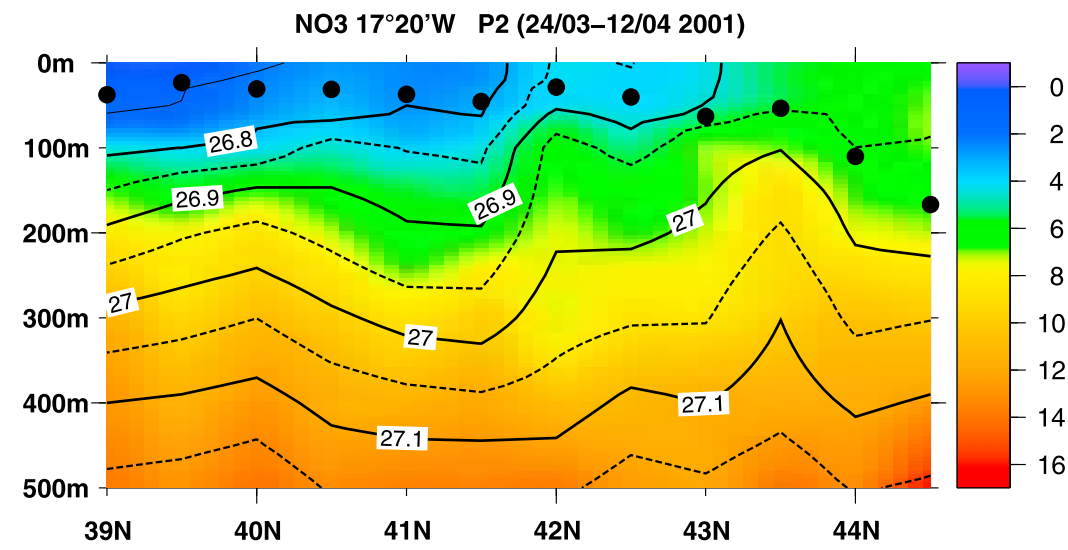

Figure 2. Section of isopycnal depths (contours for $\sigma$ surfaces) and nitrate (color scale in $\mathrm{mMol} \mathrm{kg}^{-1}$ ) along $17^{\circ} 20^{\prime} \mathrm{W}$ during $\mathrm{P} 2$. The actual mixed layer depths ( 0.02 density jump criterium) are indicated by dots. 

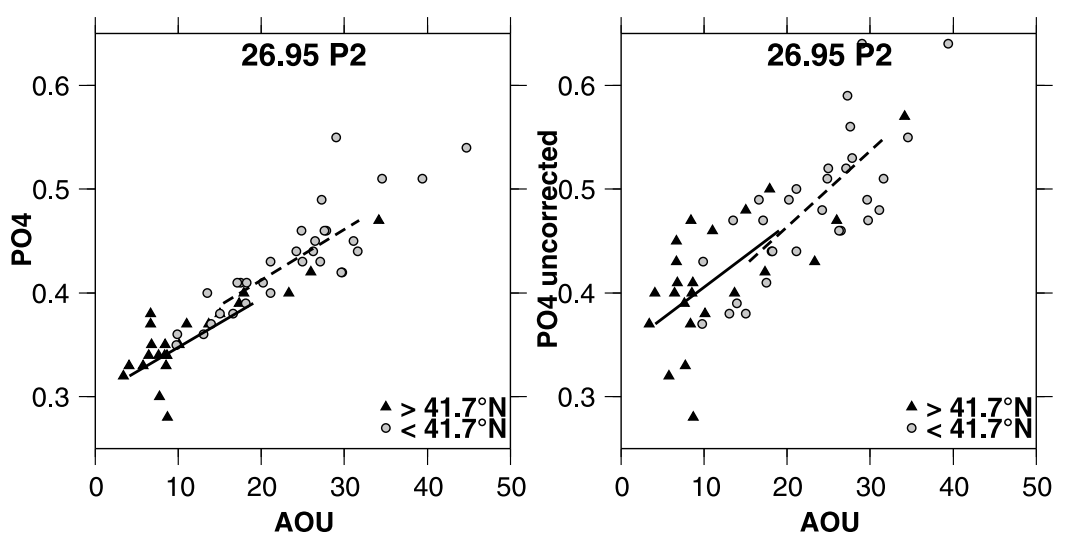

Figure 3. Scatterplots (phosphate, AOU) on $\sigma$ surface 26.95 during P2. Stations north (solid line) and south (dashed line) of $41.7^{\circ} \mathrm{N}$ are considered separately with the lines corresponding to linear regressions. (left) Scatterplot with correction on phosphate and (right) scatterplot without correction.

latitude range. Differences of properties (isopycnal depths, water masses, nutrients, primary production) have been noted between the northern and southern parts of the domain [Reverdin et al., 2005; Fernández et al., 2005b]. Mode water were formed locally in the $\sigma$ range [26.80, 27.05] [Gaillard et al., 2005], with the range [26.85, 27.05] remaining afterward below the euphotic zone.

\subsection{Data}

[8] We will rely mostly on data collected during CTD casts during the R/V Atalante cruises P1, P2, and during the $\mathrm{R} / \mathrm{V}$ Thalassa cruise $\mathrm{P} 3$, because they offer the largest range of nutrient data, both inorganic or organic (dissolved or particulate). There were also inorganic nutrient data during the P1 and P2 surveys of R/V d'Entrecasteaux, but unfortunately the oxygen data were not correct, and those will not be used here. Data collected during the previous cruise P0 in the early autumn 2000 by the R/V Thalassa and which have a less dense vertical sampling will only be used to check results from $\mathrm{P} 3$.

[9] We consider the inorganic species nitrate (nitrite), phosphate, and total dissolved inorganic carbon (DIC) for which we have the largest data set. DIC was analyzed on board soon after collection using a coulometric titration method following Johnson et al. [1985] updated by Goyet and Hacker [1992] and compared regularly with international standards (water standards provided by Andrew Dickson, Scripps Institute of Oceanography). DIC accuracy should be usually better than $3 \mu \mathrm{M} \mathrm{kg}^{-1}$. This upper range of uncertainty is confirmed by comparisons with DIC derived from alkalinity and $\mathrm{pH}$ measurements on the same bottles by González Dávila et al. [2005].

$[10]$ Nitrate $\left[\mathrm{NO}_{3}^{-}\right]$, nitrite $\left[\mathrm{NO}_{2}^{-}\right]$and phosphate $\left[\mathrm{PO}_{4}^{3-}\right]$ were analyzed following Treguer and LeCorre [1975] from 20-ml polyethylene flasks using a Technicon analyzer immediately after sampling. A unique type of in-house standard was used from P1 to P3 which was regularly compared to commercial products (Ocean Scientific International, Ltd.) [Fernández et al., 2005a]. However, this standard did not cover the concentration range investigated here. The issue was clearly worse for phosphate resulting in a large dispersion of the data, but could also be noticed for nitrate. The deep subsurface phosphates of P1 and P2 are larger by 10 to $20 \%$ than for the other cruises.

[11] To identify the biases, we considered nutrient data from the Ovide 2002 cruise collected in the same region a year later (June 2002) (P. Morin, personal communication, 2008). We also considered other recent cruises in the region. These data suggest a small scatter of properties at depths $1500-2000 \mathrm{~m}$ (typically $6 \%$ standard deviation) that is not significantly correlated to salinity or oxygen. We decided to apply by station a correction factor that results in adjusting the station 1500-2000 m values to the Ovide 2002 averaged value. This results in a very large reduction in noise on phosphate, illustrated by the scatterplot of phosphate versus apparent oxygen utilization (AOU) on the $26.95 \sigma$ surface during P2 (Figure 3). For nitrate, there is no reduction in the property scatter on isopycnal surfaces. The correction factor on nitrate results in an average decrease of $2 \%$ during P1 and P2 and an increase of $2 \%$ during P3 compared to the uncorrected values, whereas the average correction for phosphate results in a decrease of $10 \%$ for $\mathrm{P} 1,14 \%$ for P2 and 19\% for P3. We do not apply corrections on nitrite, which are large only in the euphotic layer. Results in this paper are with the corrective ratio applied to the inorganic nutrients. This is a questionable assumption, as at low nutrient values (near the surface for P2), we expect the correction to become proportionally very small. For nitrate, not applying the corrections should not result in large differences, when comparing P1 and P2, but more when comparing with $\mathrm{P} 3$. For phosphate, the differences are large and the comparison of results for different cruises are more questionable. We will refer to dissolved inorganic phosphorous (DIP) for $\left[\mathrm{PO}_{4}^{3-}\right]$ and dissolved inorganic nitrogen (DIN) for $\left[\mathrm{NO}_{3}^{-}\right]+\left[\mathrm{NO}_{2}^{-}\right]$(excluding $\left[\mathrm{NH}_{4}^{+}\right]$which is usually a small term away from the base of the euphotic zone).

[12] Organic nutrients measured on a subset of stations during P1, P2 and P3 were also used. Total organic nitrogen (TON), total organic phosphorus (TOP), and total organic carbon (TOC) were obtained by a wet oxidation technique [Raimbault et al., 1999a]. During P2, most of the measurements are for the upper $100 \mathrm{~m}$ of the water column (i.e., above the mode waters), with only two deeper stations in the southern part of the domain (also, a few other stations 
done a few weeks later). Unrealistically large values of TOC or TON were removed, as they are likely to have resulted from contamination during handling. The TOC values are often somewhat noisy, but the average profiles fit well with more complete measurements of TOC presented by Sohrin and Sempéré [2005]. Particulate organic nitrogen (PON), phosphorus (POP) and carbon (POC) were also measured on a larger set of stations by wet oxidation technique [Raimbault et al., 1999b]. They show usually less scatter than the total organic measurements, in particular for nitrogen. Dissolved organic concentrations are estimated by removing from the total concentration the particulate concentration. These data don't present the same coverage and therefore do not allow the same in depth study on isopycnal surfaces. They are presented in Appendix A. In addition and to verify some of the assumptions, we considered the more complete set of TOC data presented by Sohrin and Sempéré [2005].

[13] Then, for each station we have a discrete set of validated nutrients at the bottle levels that we interpolate either at discrete $\sigma$ levels or as a continuous profile to estimate a vertical average. We do this by linear interpolation of the bottle data in $\sigma$ coordinate. Bottles are fairly separated below $100 \mathrm{~m}$, with nutrient and DIC samples collected usually during P1, P2, and P3 near 160 (150 for P2), 200, 300, 400, 600, 800, 1000, 1250, 1500, and 2000 ( $\mathrm{m}$ for P3 and dbar for P1 and P2). As long as this vertical sampling is obtained, linear interpolation in $\sigma$ coordinates for the levels considered introduces errors that are less than the uncertainties due to the corrections factors on nitrate or phosphate, and even for $\mathrm{O}_{2}$ are often small (less than $2 \mu \mathrm{M}$ $\mathrm{kg}^{-1}$ ), as was tested on continuous oxygen profiles from associated CTD casts. However, when one level is missing, errors can be larger and we chose to reject the estimate. To summarize, resulting errors on oxygen is mostly the one associated to interpolation just described, for inorganic nutrients, it is the combination of the interpolation error and analytical error $\left(0.015 \mu \mathrm{M} \mathrm{kg}^{-1}\right.$ for phosphate and $0.2 \mu \mathrm{M} \mathrm{kg}^{-1}$ for nitrate), and of the error related to the correction technique that could be on individual profiles of $6 \%$, thus on the order of $0.04 \mu \mathrm{M} \mathrm{kg}^{-1}$ for phosphate and $0.6 \mu \mathrm{M} \mathrm{kg}^{-1}$ for nitrate. This later error dominates the error budget.

\subsection{Methods}

[14] The paradigm for our approach is that, when the mixed layer retreats, the $\sigma$ surfaces get their properties as the average mixed layer value at that time. We will refer to the properties at the time of mixed layer retreat preformed values. The expectation is that afterward because the $\sigma$ surfaces considered are below the euphotic zone, there is no more photosynthesis and that later changes on isopycnal surfaces result mostly from lateral mixing and biogeochemical fluxes (remineralization of organic matter for inorganic nutrients; respiration and oxidation for dissolved oxygen). There are two approaches to access the preformed values, either from the later (P2) subsurface scatterplots nutrient/ AOU on $\sigma$ surfaces, or from the earlier (P1) upper ocean values. Differences between the two can be indicative of processes happening between the two surveys, but mostly between P1 and the time of mixed layer retreat.
[15] The first approach works if there a nearly linear relation between AOU (the deviation of oxygen concentration from the oxygen saturation value) and inorganic nutrients, at least where water has been recently subducted. The method is to extrapolate linearly the subsurface nutrient distribution to specified AOU estimated at the time of mixed layer retreat $\left(\mathrm{AOU}^{\mathrm{i}}\right)$. The uncertainty originates to some extent to the unknown on $\mathrm{AOU}^{\mathrm{i}}$. It provides reasonable results only if some of the data points correspond to waters that have been partially renewed from the mixed layer in the same year. Because of that, we restrict the estimation for $\sigma$ surfaces $26.95-27.05$ north of $41.5^{\circ} \mathrm{N}$, and for surfaces $26.80-26.90$ south of $41.5^{\circ} \mathrm{N}$, areas where these respective waters were actually formed in large volume [Gaillard et al., 2005; Reverdin et al., 2005].

[16] The second approach is to estimate near-surface properties during winter survey P1 (as a function of density). The issue there is how the profiles are integrated vertically (to which depth). P1 takes place before the deepest mixed layers observed, which were usually found in early March, and which would have vertically homogenized near surface properties. We will assume that this mixing depth corresponds to the depth of the potential density corresponding to maximum surface density attained before the mixed layer retreat, and will average vertically from the surface to that depth to provide an estimate of near-surface properties in P1. Based on Gaillard et al. [2005] study as well as surface fields [Caniaux et al., 2005], the maximum mixed layer density can be between $(d \sigma) 0.02$ to $0.05 \mathrm{~kg} \mathrm{~m}^{-3}$ higher than what is observed at $50 \mathrm{~m}$ during the $\mathrm{P} 1$ survey $(\sigma)$. For each P1 station, we thus estimate vertically averaged nutrients from the surface to the mixed layer (ML) for two choices of $d \sigma\left(d \sigma 1=0.02 \mathrm{~kg} \mathrm{~m}^{-3}\left(\mathrm{ML}^{1}\right)\right.$ and $d \sigma 2=$ $\left.0.05 \mathrm{~kg} \mathrm{~m}^{-3}\left(\mathrm{ML}^{2}\right)\right)$. We then group these upper layer values by classes of $\sigma+d \sigma$.

[17] The subsurface scatterplots on $\sigma$ surfaces will also be compared between spring and summer surveys to estimate subsurface remineralization of inorganic nutrients in spring and summer. The assumption here is that we neglect the changes due to mixing or advection.

\section{Results}

\subsection{Mode Water Biochemical Properties at Formation Time}

[18] Both for P1 and P2, on subsurface $\sigma$ surfaces, we find a close relation between inorganic nutrients (DIN, DIP, DIC) and AOU, in particular in the northern area, and even more so during P2. We estimate the major axis of these distributions including only data points corresponding to AOU smaller than $20 \mu \mathrm{M} \mathrm{kg}^{-1}$ to estimate preformed nutrient values at $\mathrm{AOU}^{\mathrm{i}}\left(\left[\mathrm{NO}_{3}\right]^{\mathrm{i}}\right.$ as stars on Figure 4). How we estimate $\mathrm{AOU}^{\mathrm{i}}$ is actually is a major source of uncertainty on the estimated preformed nutrients that we will now discuss.

[19] During P1, there was a noticeable undersaturation of oxygen in the surface layer $(50 \mathrm{~m}$ been taken as representative of this layer), which is on the order of $2 \mu \mathrm{M} \mathrm{kg}^{-1}$ for the lighter surfaces, but is larger for the higher densities (close to $3 \mu \mathrm{M} \mathrm{kg}^{-1}$ for $\sigma 26.95$, and $6.6 \mu \mathrm{M} \mathrm{kg}^{-1}$ at 27.05, Table 1). This is expected for a period when the mixed layer usually deepens (entraining undersaturated deeper water) 

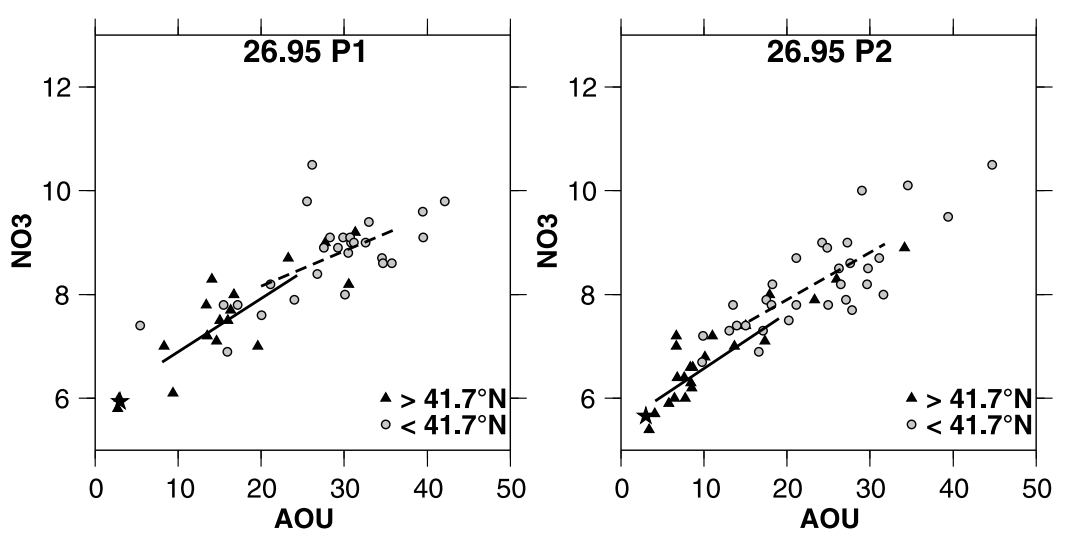

Figure 4. Scatterplots (nitrate, AOU) on $\sigma$ surface 26.95 during (left) P1 and (right) P2. The lines correspond to linear regression done separately for stations north (solid line) and south (dashed line) of $41.7^{\circ} \mathrm{N}$. The stars correspond to the estimated preformed nitrate.

and cools, and when photosynthesis is not very large. During P1, there is both a mixed layer deepening and a decrease in photosynthesis toward the north and the higherdensity surface waters [Gaillard et al., 2005; Claustre et al., 2005], so that undersaturation is more pronounced in the north (not shown). The near surface undersaturation could evolve during the few weeks between P1 and the effective time of water formation, either through gas exchange at the sea surface and primary production that would increase oxygen, or through entrainment of deeper water that would decrease dissolved oxygen. Koeve [2001] provides evidence at the biotrans site $\left(47^{\circ} \mathrm{N} / 20^{\circ} \mathrm{W}\right)$ slightly to the north (and thus with denser surface water) for an undersaturation of $2 \%$ (with 1.5\% uncertainty); thus roughly a positive AOU of $5 \mu \mathrm{M} \mathrm{kg}^{-1}$, within the range adopted here. Based on his uncertainty estimate and observed scatter during P1 survey, the estimates we provide for $\mathrm{AOU}^{\mathrm{i}}$ based on the P1 survey have an uncertainty on the order of 1.5 to $3 \mu \mathrm{M} \mathrm{kg}^{-1}$.

[20] Values of preformed nutrients estimated from P2 increase with density. They have fairly low uncertainties as there are many stations with low AOU that have been at least partially renewed recently from the mixed layer. Close estimates are obtained from P1 subsurface data (Figure 4 and Table 1) but generally with a larger uncertainty (except for 26.85), as there are less P1 data with low AOU on subsurface isopycnals, indicative of less subsurface renewal in this early part of the winter, taking place before most intense mixing usually happened and effective subduction occurs.

\subsection{Nutrients Before Subduction}

[21] P1 near surface nutrient values estimated according to the method described in section 2.3 increase with $\sigma+d \sigma$ (Table 1), as was earlier found at the surface by [Fernández et al., 2005a]. The two criteria on $d \sigma$ produce usually fairly similar values, and only the one corresponding to the most realistic $d \sigma$ for the particular part of the domain is reported. For 26.85 (southern part of the domain), however, the results with the two criteria are rather different, as the stations selected by the two criteria are to a large extent not the same. This is also an area, where large biological consumption had already happened before/during $\mathrm{P} 1$, resulting in more patchy distributions [Fernández et al., 2005b].

[22] The P1 near surface values are usually found to be close in magnitude to the preformed values estimated from P2 distributions (Table 1). There is a systematic tendency for DIP that the P1 mixed layer values are equal or a little less, but that for DIN and DIC they are larger. At 26.8026.85 , the positive difference for DIN is noticeable when we adopt the $\mathrm{ML}^{1}$ solution, and not the $\mathrm{ML}^{2}$ solution. However, the $\mathrm{ML}^{1}$ is probably more realistic for these light waters which tended to restratify earlier than further north. This hints for a small primary production between P1 and the mixed layer retreat that we will discuss later in section 4 .

Table 1. Preformed Nutrients on Subsurface $\sigma$ Surfaces for Cruises P1 and P2, as Well as Near-Surface Nutrients During P1 Sorted by $\sigma$ Classes According to $\sigma(50 \mathrm{~m})+d \sigma^{\mathrm{a}}$

\begin{tabular}{|c|c|c|c|c|c|c|c|c|c|}
\hline & \multicolumn{3}{|c|}{26.85} & \multicolumn{3}{|c|}{26.95} & \multicolumn{3}{|c|}{27.05} \\
\hline & $x^{i} P 1$ & $x^{i} \mathrm{P} 2$ & $\mathrm{ML}^{1}$ & $x^{i} \mathrm{P} 1$ & $x^{i} \mathrm{P} 2$ & $\mathrm{ML}^{2}$ & $x^{i} P 1$ & $x^{i} P 2$ & $\mathrm{ML}^{2}$ \\
\hline$n$ & 20 & 26 & 7 & 17 & 23 & 17 & 26 & 26 & 4 \\
\hline $\mathrm{AOU}$ & 2. & 2. & $1.8,1.3$ & 3. & 3. & $2.3,0.8$ & 5. & 5. & $6.6,0.8$ \\
\hline $\mathrm{NO}_{3}$ & $4.96,0.22$ & $4.21,0.21$ & $4.26,0.20$ & $5.94,0.23$ & $5.66,0.17$ & $5.89,0.10$ & $7.01,0.22$ & $7.28,0.15$ & $7.50,0.11$ \\
\hline $\mathrm{NO}_{2}$ & & & $0.14,0.008$ & & & $0.12,0.01$ & & & $0.05,0.006$ \\
\hline $\mathrm{PO}_{4}$ & $0.230,0.04$ & $0.232,0.008$ & $0.220,0.01$ & $0.317,0.02$ & $0.313,0.01$ & $0.302,0.008$ & $0.316,0.03$ & $0.382,0.01$ & $0.368,0.01$ \\
\hline DIC-2000 & $96.8,5.0$ & $96.0,0.5$ & 98.30 .3 & 104.00 .6 & 102.42 .0 & 103.60 .6 & 113.91 .0 & 107.61 .2 & 113.71 .9 \\
\hline
\end{tabular}

${ }^{a}$ Subsurface $\sigma$ surfaces are located below $100 \mathrm{~m}$ depth. Here $\mathrm{x}^{\mathrm{i}} \mathrm{P} 1$ is cruise $\mathrm{P} 1$ and $\mathrm{x}^{\mathrm{i}} \mathrm{P} 2$ is cruise $\mathrm{P} 2$. Near-surface nutrients during $\mathrm{P} 1$ are vertically averaged from sea surface to the level with $\sigma(50 \mathrm{~m})+d \sigma$; ML1 $d \sigma=0.02$; ML2 $d \sigma=0.05$. Only the most relevant choice is retained for each density. The number of stations $(n)$ is reported, as well as for each nutrient, the average (first value) and uncertainty standard deviation (second value) estimates. For ML1 and ML2, AOU refers to average AOU at the depth $50 \mathrm{~m}$. The surface 26.85 includes stations south of $41.7^{\circ} \mathrm{N}$, whereas the surfaces 26.95 and 27.05 include stations north of $41.7^{\circ} \mathrm{N}$. DIC-2000 is the DIC with $2000 \mu \mathrm{M} / \mathrm{kg}$ removed. 
Table 2. Averages of Nutrient and AOU on $\sigma$ Surfaces $^{\mathrm{a}}$

\begin{tabular}{|c|c|c|c|c|c|c|c|c|c|c|c|c|}
\hline & \multicolumn{4}{|c|}{26.85} & \multicolumn{4}{|c|}{26.95} & \multicolumn{4}{|c|}{27.05} \\
\hline & $x^{i}$ & $\mathrm{P} 1$ & $\mathrm{P} 2$ & $\mathrm{P} 3$ & $x^{i}$ & $\mathrm{P} 1$ & $\mathrm{P} 2$ & $\mathrm{P} 3$ & $x^{i}$ & $\mathrm{P} 1$ & $\mathrm{P} 2$ & $\mathrm{P} 3$ \\
\hline$n$ & & 20 & 26 & 18 & & 17 & 23 & 31 & & 26 & 26 & 37 \\
\hline $\mathrm{NO}_{3}$ & 4.21 & 6.05 & 5.47 & 7.14 & 5.66 & 7.53 & $6.74,7.94(1.40)$ & 8.95 & 7.28 & 10.6 & $10.49,7.87(0.30)$ & 11.38 \\
\hline $\mathrm{PO}_{4}$ & 0.232 & 0.305 & 0.295 & 0.357 & 0.313 & 0.387 & $0.359,182(25)$ & 0.464 & 0.382 & 0.546 & $0.548,154(7)$ & 0.599 \\
\hline DIC-2000 & 96.0 & 108.9 & $\begin{array}{c}102.4 \\
1.59(0.13)\end{array}$ & 113.3 & 102.4 & $\begin{array}{c}111.4 \\
1.72(0.30)\end{array}$ & $\begin{array}{c}108.4 \\
1.57(0.45)\end{array}$ & 118.3 & 107.6 & $\begin{array}{c}126.6, \\
2.04(0.15)\end{array}$ & $\begin{array}{c}123.0 \\
1.54(0.30)\end{array}$ & 129.5 \\
\hline $\mathrm{AOU}$ & 2 & 18.4 & 12.0 & 23.5 & 3 & 16.2 & 11.5 & 26.5 & 5 & 30.9 & 30.2 & 38.5 \\
\hline
\end{tabular}

${ }^{a}$ Here $\sigma$ surfaces are below $100 \mathrm{~m}$. The first value is the average; the second value is the slope for the distribution AOU:nutrient, when they can be estimated, as well as its uncertainty standard deviation (in parentheses). Here $\mathrm{x}^{\mathrm{i}}$ refers to the preformed values estimated from the P2 distributions. The surface 26.85 includes stations south of $41.7^{\circ} \mathrm{N}$, whereas the surfaces 26.95 and 27.05 include stations north of $41.7^{\circ} \mathrm{N}$. DIC-2000 is the DIC with $2000 \mu \mathrm{M} / \mathrm{kg}$ removed.

\subsection{Evolution of Mode Waters Biochemical Properties After Subduction}

[23] The average values of nutrients on subsurface $\sigma$ surfaces are usually smaller during P2 than P1 (Table 2 and Figure 5). This is not surprising as P2 incorporates more stations that have been recently subducted from the mixed layer with lower (preformed) nutrient content. Therefore P2 average values are closer to near surface (ML) values during $\mathrm{P} 1$ than the P1 subsurface values. The relative difference is much smaller for $\mathrm{P}$ than for $\mathrm{N}$ or DIC.
[24] Late summer P3 (but also during P0 in the autumn 2000) nutrients/AOU values are much larger than during P2 (Table 2 and Figure 5), and also they occupy a smaller range in AOU (Figure 6). For the 26.95 surface largest changes are found in the northern part of the domain with a $15.0 \mu \mathrm{M}$ $\mathrm{kg}^{-1}$ change in AOU, compared with $6.9 \mu \mathrm{M} \mathrm{kg}^{-1}$ in the southern part of the domain. The changes are such that in the northern part of the domain the DIP and DIN distributions as a function of AOU are found above those in the southern part of the domain during P3 (Figure 6), and not
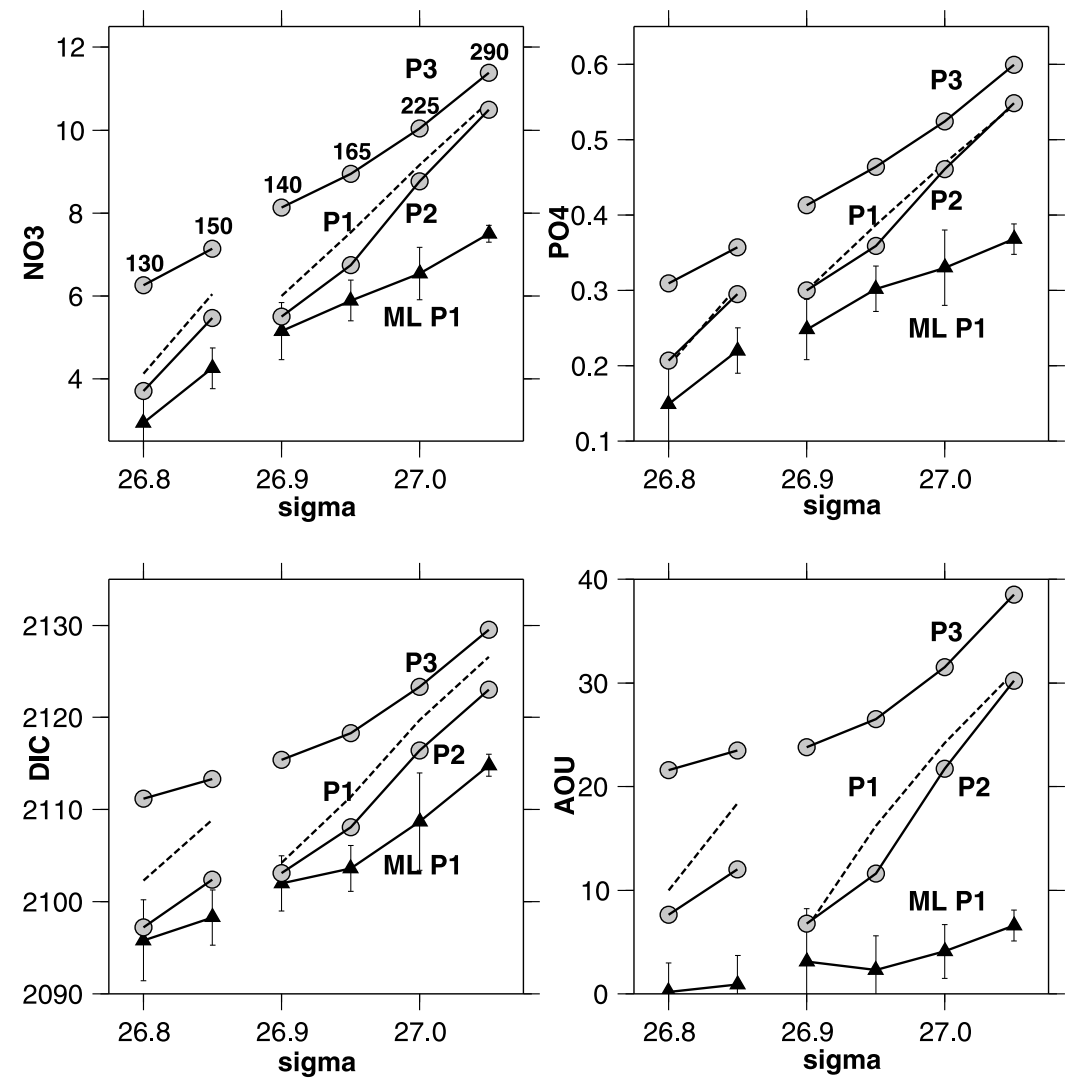

Figure 5. Average properties (nitrate, phosphate, DIC, AOU) as a function of density for the different surveys (for $\sigma$ less than 26.9, surveys are in southern part of the domain; for $\sigma$ larger or equal to 26.9, surveys are in northern part of the domain). ML P1 refers to P1 near-surface averages with $\mathrm{ML}^{1}$ (for $\sigma$ less than 26.9) or $\mathrm{ML}^{2}$ (for $\sigma$ equal or larger than 26.9). The bars correspond to a $2 \times$ root-mean-square deviation range on individual values. Subsurface averages are presented for the different surveys (P2 and $\mathrm{P} 3$ is solid line with circles; $\mathrm{P} 1$ is dotted line). Average depths are indicated for P3 on the nitrate plot. 


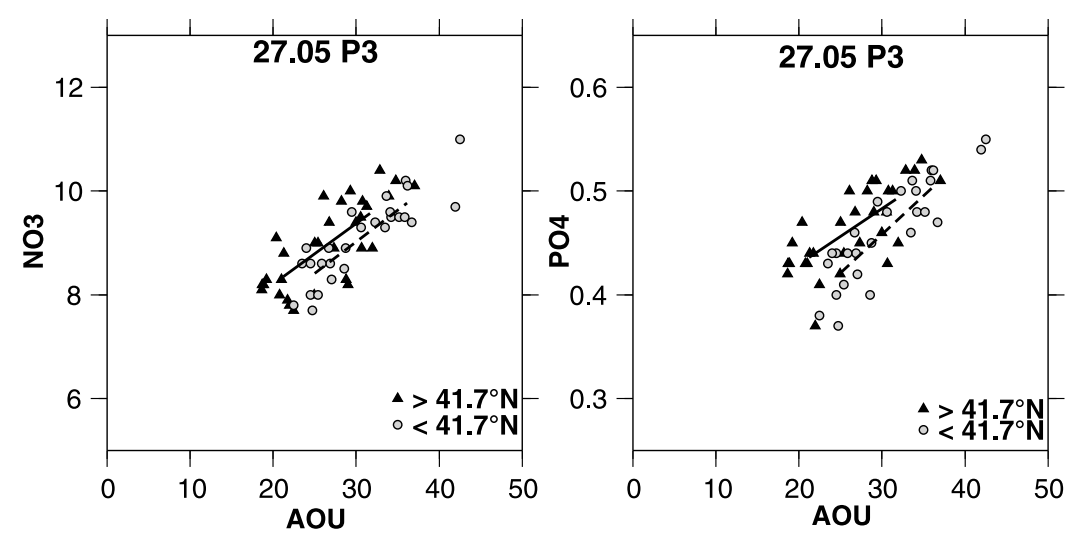

Figure 6. Scatterplots on $\sigma$ surface 26.95 during P3: (left) nitrate and AOU and (right) phosphate and AOU. The lines correspond to linear regression done separately for stations north (solid line) and south (dashed line) of $41.7^{\circ} \mathrm{N}$.

nearly aligned along one common regression line as during P2 (Figures 3 and 4). On the other hand, the distributions for DIC remain aligned. This is also found on other surfaces, albeit to a lesser extent on the deeper surfaces, as 27.05 or denser.

[25] These different regression lines during $\mathrm{P} 3$ for the northern and southern parts of the domain in the (DIN, AOU) or (DIP, AOU) scatterplots are also found, but to a lesser extent, during P0 in the preceding late summer (for DIN and DIP, not shown). They are not associated with significant changes in salinity or stratification with respect to $\mathrm{P} 1$ or $\mathrm{P} 2$, nor are they found for DIC, with a large contrast remaining between northern and southern water masses, both due to origin, but also differences in ventilation [Reverdin et al., 2005]. The larger changes experienced in these waters in the northern part of the domain, are therefore likely to be caused primarily by biological/chemical processes, part of the seasonal cycle.

[26] These biogeochemical processes could already have left some imprint on the distributions during P2. For example, on 27.05 where we are aware that there has been some renewal during late winter mixed layer retreat, the smallest AOU values of 10 are much larger than $\mathrm{AOU}^{\mathrm{i}}$. This could be indicative of early remineralization, albeit isopycnal mixing with older waters having higher $\mathrm{AOU}$ also contributes to the increase of AOU.

\section{Discussion}

\subsection{Large Preformed Nutrients in Mode Waters}

[27] The POMME estimates of DIN and DIC preformed values are large and of similar magnitude than the $\mathrm{P} 1$ winter values. This is consistent with model results in the area [Lévy et al., 2005; K. Karleskind et al., unpublished manuscript, 2009], and very different from the situation in the North Atlantic subtropical mode water, which has depleted nutrients at the time of its formation as the result of primary production [Palter et al., 2005]. Nonetheless, we found that DIC and DIN preformed values are a little lower than the P1 near-surface values. For DIC, changes could result from gas exchange of $\mathrm{CO}_{2}$ during that period. As the surface layer is undersaturated in carbon dioxide, and winds are often strong, the gas exchanges are large that could increase DIC [González Dávila et al., 2005; Merlivat et al., 2009]. Model studies suggest that the effect is in the range of 0.6 to $1 \mu \mathrm{M} \mathrm{kg}^{-1}$ over a 20 day period, if redistributed over a mixed layer with depth in the range $[150,200] \mathrm{m}$, as is typical before subduction in the area (K. Karleskind et al., unpublished manuscript, 2009). This would slightly increase near-surface DIC, and therefore the preformed DIC as estimated from P2 subsurface data, thus the opposite of what is observed. Are these differences between the winter estimates and the preformed nutrients the result of moderate consumption of inorganic nutrients by primary production between P1 and the time of effective subduction?

[28] Primary and new production in the surface layers was witnessed during periods with moderate winds in the second part of February before mode water formation as well as after 10 March [Maixandeau et al., 2005; Fernández et al., 2005b]. Estimates [Fernández et al., 2005b] of new production between P1 survey and the time of subduction suggest a removal on the order of 1.5 to $2.5 \mu \mathrm{M} \mathrm{kg}^{-1}$ for DIC and 0.11 to $0.25 \mu \mathrm{M} \mathrm{kg}^{-1}$ for DIN, with mixed layer depths between 150 and $200 \mathrm{~m}$ and an average length of 23 days. The magnitude of this removal is in the bulk range of what is expected from the difference in Table 1 between P1 near-surface estimates and preformed nutrients, both for DIN and DIC, except maybe for a too large DIC change estimated on 27.05.

[29] Particle fluxes measured by four sediment trap moorings in the POMME area near $400 \mathrm{~m}$ (therefore, below the layers considered here) indicated little export in midFebruary, but increasing in early March [Guieu et al., 2005]. This contains a majority of carbonate material, but roughly with a $20 \%$ content in organic particulate matter. This particulate matter was converted from the dissolved DIC and DIN pools by production in the near-surface layer before the effective time of subduction. There is also a large increase in the pool of organic nutrients near the surface between P1 and P2 (Appendix A). This is indicative of a drawdown of inorganic nutrients, but we don't know whether this happened before or after the effective subduction of mode waters. Surface chlorophyll distributions [Lévy et al., 2005] as well as export in the sediment traps suggest that the bulk of this increase is happening later on. 
[30] As a note of caution on this discussion, the estimated error on initial $\mathrm{AOU}^{\mathrm{i}}$ commented in 3.1 translates into errors in preformed nutrients of $0.18 \mu \mathrm{M} \mathrm{kg}^{-1}$ for DIN, $0.012 \mu \mathrm{M}$ $\mathrm{kg}^{-1}$ for DIP and $1.0 \mu \mathrm{M} \mathrm{kg}^{-1}$ for DIC. They are nearly as large as the observed differences for DIN, larger for DIP, and as large for DIC, except for the deepest $\sigma$ surfaces (27.00 and 27.05).

\subsection{Subsurface Remineralization}

[31] We found large differences in nutrients in the mode waters from spring to late summer. Where does it originate from? Isopycnal subsurface changes between the different surveys could result from horizontal advection, diapycnal mixing, or remineralization processes. Although horizontal advection could certainly contribute, there is no associated major change in temperature-salinity properties between P2 and P3 [Reverdin et al., 2005] suggesting that water masses remained relatively similar, in particular in the northern part of the domain. Diapycnal diffusion (vertical mixing) is usually smaller after restratification according to spring and summer estimates in the north of domain [BouruetAubertot et al., 2005]. Therefore we expect that the bulk of the changes in dissolved nutrients in the mode waters are related to remineralization. This could originate either from remineralization of the preformed (initial) excess dissolved organic pool at the time of effective mode water formation, or from remineralization of falling particulate matter.

[32] Appendix A provides estimates of what could have been the composition of the preformed labile organic matter. Assuming it remineralizes in Redfield stoechiometry, this would contribute an $8 \mu \mathrm{Mol} \mathrm{kg} \mathrm{kg}^{-1}$ increase in AOU. However, only a percentage of the mode waters are renewed each year. Taking the example of the 26.95 isopycnal, typical of the large-volume mode water formed locally, we find in the northern part of the domain that no more than $65 \%$ of this water is directly ventilated in 2001 . Thus, the contribution of the initial dissolved organic pool should contribute to an increase in AOU on the order of $5 \mu \mathrm{M} \mathrm{kg}^{-1}$ (assuming it mostly happens between P3). This can be compared to the observed AOU change of $15 \mu \mathrm{M} \mathrm{kg}^{-1}$, therefore with these hypotheses the contribution of dissolved organic matter (DOM) is one third of the observed AOU change on this surface. This analysis assumes a constant pool of preformed dissolved organic matter independent of potential density. For checking this assumption, we considered a larger set of TOC data [Sohrin and Sempéré, 2005] which is sufficient to carry the same analysis (estimates of preformed values, analysis on isopycnal surfaces) as for the inorganic nutrients, and to which we can subtract POC values (Appendix A). According to these data, there is no strong dependence of TOC or dissolved organic carbon (DOC) in the near-surface layer during P1, except for a small diminution at 27.00 or higher (not exceeding $2.5 \mu \mathrm{M} \mathrm{kg}^{-1}$ ). For the 26.95 surface, we find no strong evidence for a change in DOC between P1 nearsurface values and P2-derived preformed values, although this is compatible with a $2 \mu \mathrm{M} \mathrm{kg}^{-1}$ decrease. There is also no evidence in this set for a decrease in DOC between P2 and P3 on 26.95 (within the uncertainties on the POC changes which exceed $2 \mu \mathrm{M} \mathrm{kg}^{-1}$ ). A similar result holds for other isopycnal surfaces with if any a slight increase in
DOC between P2 and P3. This reinforces our analysis that remineralization of preformed dissolved organic matter pool should contribute only a small portion of the changes in AOU and inorganic nutrients observed in the mode waters between $\mathrm{P} 2$ and $\mathrm{P} 3$.

[33] Therefore the observed change in AOU of the mode waters implies a large contribution of remineralization of particulate organic matter originating in the upper water column. Part of this could be from small particles already detrained at the end of winter and been mostly advected with the currents: however based on the estimate from P1, this pool is not very large, typically one third of the labile dissolved pool. The other part would be from larger particles that sink downward with respect to the currents. Vertical particle fluxes have been observed to be large at $400 \mathrm{~m}$ throughout April to June during and after the P2 survey, in particular in the northern part of the domain [Guieu et al., 2005]. An uncertain part of the fluxes has been remineralized or dissolved above the particle traps in the mode waters. For instance, sediment trap data from the leg 2 of P2 in late April to early May) present a strong decrease of the particulate $\mathrm{C}$ (and even more $\mathrm{N}$ ) between 200 and $400 \mathrm{~m}$, across the mode water layer $(68 \%$ of the PON flux at $200 \mathrm{~m}$ reaches $400 \mathrm{~m}$ [Goutx et al., 2005]). Retaining this percentage, the corrected flux estimated during POMME by two sediment traps at $400 \mathrm{~m}$ in the northern part of the domain [Guieu et al., 2005], as well as an average $C: N$ ratio of $6: 1$ in the particulate fraction [Goutx et al., 2005], the average remineralization between $\mathrm{P} 2$ and $\mathrm{P} 3$ of $0.72(0.12) \mu \mathrm{M} \mathrm{kg}^{-1}$ for $\mathrm{C}(\mathrm{N})$ between 200 and 400 $\mathrm{m}$. This is only a small $(\sim 15 \%)$ fraction of the changes observed for the 27.05 isopycnal which is in the core of that layer (Table 2), but there is a large leeway on this value by almost a factor 2 (resulting from the short-term average of estimates from only two traps), so that this could easily be compatible with a contribution of $25 \%$. We cannot extrapolate further up in the water column, as we don't know to which extent the remineralization/dissolution increases upward.

[34] These estimates do not close the budget of the observed changes, but indicate a strong contribution of remineralization of particulate organic matter (POM), and a probably strong contribution of DOM to the actual seasonal changes.

\subsection{Redfield Ratios}

[35] In the previous discussion, we have assumed stoechiometric Redfield ratios. However, the data on Tables 1 and 2 suggest fairly large deviations from this relation both for the initial drawdown of inorganic nutrients before subduction and for the remineralization, which we will review.

[36] New production between P1 and the effective subduction is expected to be the main source for the observed changes in inorganic nutrients during this period. Estimates of new production for the winter season of Fernández et al. [2005b] indicate $\mathrm{C}: \mathrm{N}$ ratios of at least 10, that are larger than the corresponding Redfield ratio, therefore suggesting production of inorganic particulate carbon by calcifying organisms during this period. The surface layer budgets during $\mathrm{P} 1$ as well as the preformed nutrient estimates from 


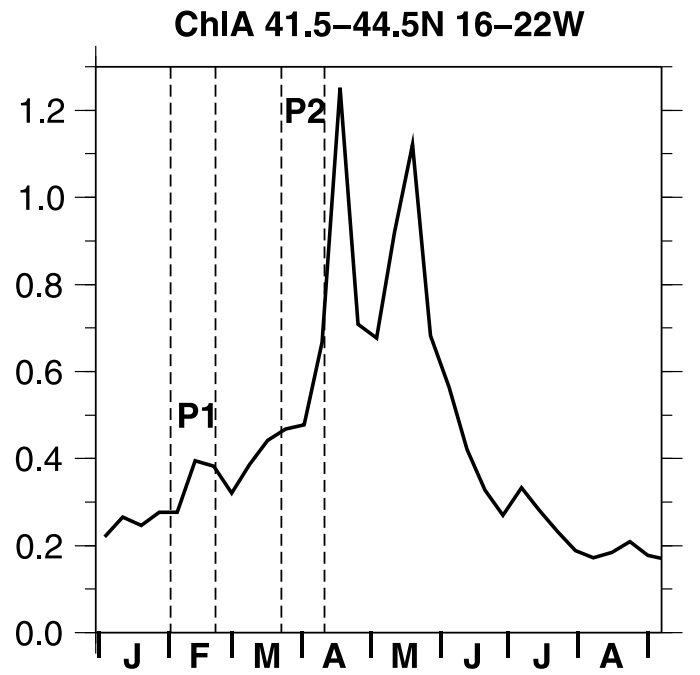

Figure 7. Average weekly ChlA estimates from SeaWiFS in 2001 in the northern part of the POMME domain $\left(41.5^{\circ} \mathrm{N}-44.5^{\circ} \mathrm{N}\right)\left(\mathrm{mg} \mathrm{m}^{-3}\right)$.

the mode waters in P2 have all large uncertainties, but the drawdown of inorganic nutrients between the two estimates is also according to large $\mathrm{C}: \mathrm{N}$ ratios of at least 10 . We have however a major difference for DIP, for which P1 nearsurface values are a little less than the preformed estimates. If we had not applied the corrections on DIP, we would have found nearly identical values between the two, so still no drawdown of DIP. We suspect that the difference between $\mathrm{P}$, $\mathrm{N}$ and DIC in this thick late winter surface layers originates from a higher rate of remineralization of organic $\mathrm{P}$ than of organic $\mathrm{N}$ or $\mathrm{C}$, with little particulate export of phosphate. Lability of the organic dissolved organic nitrogen (DON) or dissolved organic phosphorus (DOP) pool was not measured during P1, but it is expected that DOP is more labile than organic DON, and that there is a larger proportion of labile DOP than for DON and even more than for DOC [Hopkinson et al., 2002].

[37] Interestingly, the nutrient increase between P2 and P3 (north of $41.5^{\circ} \mathrm{N}$ ) on $\sigma 26.95$ (but also other surfaces) indicated Redfield ratios close to stoechiometric for $\mathrm{C}$ :AOU (1:1.5), a little larger for P:AOU (1:143, compared to a stoechiometric Redfield ratio 1:172), and much larger for $\mathrm{N}$ :AOU (1:6.8, instead of a stoechiometric Redfield ratio of $1: 10.8)$. For $\mathrm{N}: \mathrm{AOU}$ and $\mathrm{P}: \mathrm{AOU}$, this is also larger than the slopes of the isopycnal distributions (N, AOU; P, AOU) during P2 (Table 2). This also implies a very low $\mathrm{C}: \mathrm{N}$ ratio for these changes of 4.5. If the corrections had not been applied on nitrate, we would have obtained a slightly smaller change in nitrate, but still a low $\mathrm{C}: \mathrm{N}$ of 5.2 and $\mathrm{N}$ :AOU of (1:7.8). If the corrections had not been applied on phosphate, the implied P:AOU would have been even larger (1:110). The differences with Redfield stoechiometry are therefore not a result of our data processing. These deviations from Redfield stoechiometry are also obtained when considering the changes between P2 and P3 on other surfaces, albeit to a lesser extent on the denser, deeper surface 27.05 (C:N of 7.3, or $\mathrm{N}$ :AOU 1.:9.3).

[38] The initial DOM, as well as the POM in the surface layer has a stoechiometric composition close to the stoe- chiometric Redfield ratios (compare to Appendix A). The larger relative changes of particulate $\mathrm{N}$ over $\mathrm{C}$ between 200 and $400 \mathrm{~m}$ [Goutx et al., 2005] are compatible with a higher remineralization of $\mathrm{N}$ over $\mathrm{C}$. We also commented that $\mathrm{P}$ is probably more labile than $\mathrm{N}$ and even more than $\mathrm{C}$ in the dissolved inorganic pool. All these would contribute to the larger observed changes of $\mathrm{P}$ and $\mathrm{N}$ than $\mathrm{C}$ compared to stoechiometric Redfield ratios in these rather shallow isopycnal horizons (130-300 m, Figure 5), and therefore the displacement from spring to late summer of the (P, AOU) and $(\mathrm{N}, \mathrm{AOU})$ distributions (Figure 6$)$ in the northern part of the domain.

\section{Conclusions}

[39] Preformed nitrate, phosphate, and inorganic carbon were estimated from early spring (P2) distributions both for the isopycnal $\sigma$ range 26.90-27.05 in the northern part of the domain and on lighter surfaces 26.80-26.85 in the southern part of the domain, which roughly correspond to the local formation areas of these water masses by late winter mixed layer retreat [Reverdin et al., 2005]. These estimates were found to be close to the nutrients in the near surface layer in late winter 2001 (P1).

[40] We have compared the upper ocean nutrients measured two weeks prior to subduction to estimates of the nutrients at the time of subduction. These two estimates have clearly similar magnitudes, with some indication for DIC and for nitrate that there might have been some consumption of nutrients between $\mathrm{P} 1$ and the subduction time. This suggests that new production would have used some of the nutrients during that time, despite the often deep layers. Such a consumption and possible export are hinted at in this region from data by Koeve [2001] and Körtzinger et al. [2001]. They are compatible with estimated new production for these cruises [Fernández et al., 2005b]. They are also commented by Lévy et al. [2005] based on model-generated mixed layer depths and Sea-viewing Wide Field-of-view Sensor (SeaWiFS) chlorophyll data. SeaWiFS data illustrate more surface chlorophyll concentrations in the southern part of the domain before early March. However, even in the northern part of the domain, the chlorophyll levels are intermediate in late February after P1 survey until a period with larger winds, deeper mixed layer and lower chlorophyll in early March preceding subduction (Figure 7). That we don't observe changes in DIP, is indicative of a more labile nature of $\mathrm{P}$ in the organic matter formed during those blooms than for $\mathrm{N}$ or $\mathrm{C}$.

[41] P1 data and considerations on the timing of new production suggest that the preformed $\mathrm{AOU}^{\mathrm{i}}$ (undersaturation) of the subducted water are less than $3 \mu \mathrm{M} \mathrm{kg}^{-1}$ for water at density 27.00 or lower, and therefore less than what is adopted by Körtzinger et al. [2001] for these lighter varieties of mode water. With these assumptions and with the limitation that $\mathrm{AOU}^{\mathrm{i}}$ is poorly constrained by the data, we estimate that on the order of $0.2-0.3$ and $2-3 \mu \mathrm{Mol}$ $\mathrm{kg}^{-1}$, respectively, for $\mathrm{N}$ and $\mathrm{C}$ where removed from the inorganic pool between $\mathrm{P} 1$ and the subduction time by new production and export. This is relatively small compared to the standing stocks. Compared to the Lévy et al. [2005] paradigm of a midlatitude regime in this region, the situation encountered in 2001 is more typical of the subpolar 


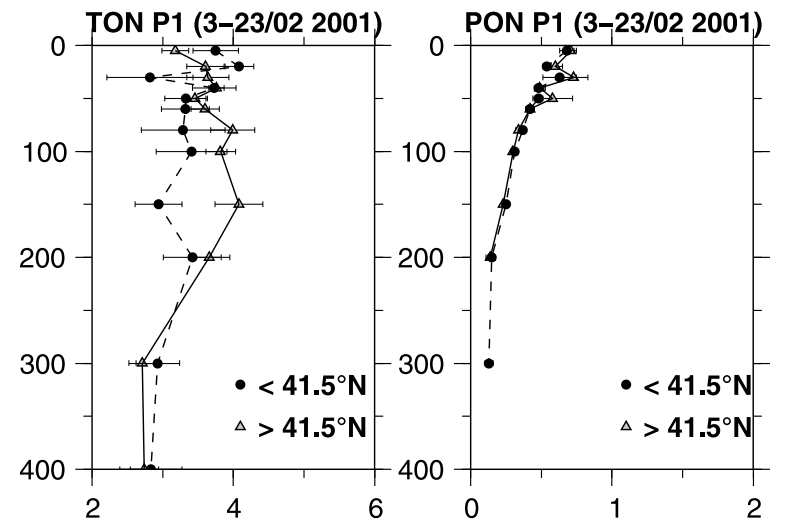

Figure A1. Vertical profiles of (left) TON and (right) PON during P1. The averages are done separately for stations north and south of $41.7^{\circ} \mathrm{N}$ and error bars on the averages are indicated.

gyre (the northern regime, where stratification happens prior to nutrient depletion). Our results indicating a moderate consumption of the nutrients prior to subduction are compatible with model estimations of nutrient subduction (Karleskind et al., unpublished manuscript, 2009).

[42] There is a large change in inorganic nutrients, DIC, and oxygen content of the newly subducted waters until P3, in particular in the northern part of the domain. Estimates of the potentially labile initial organic pool at the time of subduction were made, although not by class of $\sigma$, because of insufficient data (except for DOC). These estimates suggest that no more than one third of the changes on isopycnal surfaces originate from the remineralization of this pool. We therefore expect a large contribution of particle fluxes that have been larger in the northern part of the domain [Guieu et al., 2005], albeit with a large spatial variability.

[43] We found during P3 different (nutrient, AOU) scatterplots in the northern part of the domain than in the southern part. This illustrates large spatial differences in a region often depicted as rather homogeneous [van Aken, 2001; Paillet and Mercier, 1997]. This did not come as a surprise, as earlier work has shown that the two subdomains had fairly isolated water masses with little direct exchange between the two regions [Le Cann et al., 2005; Reverdin et al., 2005], and that the two regions have a different production history.

[44] Comparisons of P2 and P3 suggest non-Redfieldian changes related to remineralization which favor $\mathrm{P}$ and $\mathrm{N}$ changes over C. The N:AOU slope during P2 (1:7.9) is less, but also favors $\mathrm{N}$ changes compared to stoechiometric Redfield ratio (1:10.8). This work has been done neglecting changes related to circulation (assuming local in situ evolution of the water mass properties). The circulation was however such that there was not much retention of the mode water over the 6-month period (except in a few coherent eddies) in particular in the eddy-richer northern part. We can therefore not rule out the influence of renewal of water masses with different inorganic N and P (but not DIC) on these results. Our results are nonetheless supported by the similarity with the situation sampled in early autumn 2000 during P0 (and with the slopes during P2), suggesting that the changes might be more related to the biological fluxes, as we hypothesized, and with preferential remineralization of $\mathrm{N}$ over $\mathrm{C}$. This is at odds with the conclusions of Körtzinger et al. [2001] a little further north suggesting less $\mathrm{N}$ compared to $\mathrm{C}$ in export production that what we find in our remineralization estimates, which they support from.surface budgets suggesting that in nearly oligotrophic situations, $\mathrm{C}: \mathrm{N}$ increases. They mention that their results are less reliable south of $42^{\circ} \mathrm{N}$ and we find smaller differences for the deeper isopycnals than for 26.95 , which could be indicative of a regime shift somewhere in the northern end of the POMME region $\left(45^{\circ} \mathrm{N}\right)$ or depth range.

\section{Appendix A: Organic Nutrients}

[45] Organic nutrients were not measured (except for TOC) with the same coverage as the inorganic nutrients, and therefore coverage is not sufficient to separate by density class, either on subsurface isopycnals or in the near-surface layer during P1. Even attempting to separate the northern and southern parts of the domain is difficult. For all cruises, the averaged profiles usually indicate increases of total organic nutrients in the surface layer compared to the deeper ocean (example for TON during P1, Figure A1), with differences between north and south that reflect differences in mixed layer depth distribution between these two parts of the domain (for P1 150-200 m, versus $100-150 \mathrm{~m}$, respectively). There is also an increase of particulate nutrients toward the surface (during P1, similar in northern and southern parts, Figure A1; during P2, larger at the surface for the southern than the northern part). These particulate nutrients contribute to the increase near the surface in total organic nutrients, and are particularly large during P2.

[46] Dissolved organic nutrients are estimated as the difference between the total and the particulate organic contents (Figure A2). During P1, we can roughly estimate which part of the near-surface layer (defined as for $\mathrm{ML}^{2}$ in Table 1) organic nutrients correspond to recent nutrients, therefore to a more labile fraction of the organic pool. We get the following average results (not separating north and south parts of the domain): (1) TON: $3.98 \mu \mathrm{M} \mathrm{kg}^{-1}$ at the surface and $2.95 \mu \mathrm{M} \mathrm{kg}^{-1}$ at subsurface, thus a $1.03 \mu \mathrm{M}$ $\mathrm{kg}^{-1}$ difference, whereas for PON there is a $0.25 \mu \mathrm{M} \mathrm{kg}^{-1}$ surface-subsurface difference, so DON contrast should be $0.78 \mu \mathrm{M} \mathrm{kg}^{-1}$; (2) TOP: a 0.07 to $0.08 \mu \mathrm{M} \mathrm{kg}^{-1}$ surfacesubsurface difference, whereas for POP, the difference is $0.03 \mu \mathrm{M} \mathrm{kg}^{-1}$, so DOP contrast should be $0.045 \mu \mathrm{M} \mathrm{kg}^{-1}$; and (3) TOC: a $7.55 \mu \mathrm{M} \mathrm{kg}^{-1}$ surface-subsurface difference, whereas for POC, the difference is $2.25 \mu \mathrm{M} \mathrm{kg}^{-1}$, so DOC contrast should be on the order of $5.3 \mu \mathrm{M} \mathrm{kg}^{-1}$.

[47] In all cruises, the particulate organic matter which strongly peaks in the surface layer (but with deeper penetration for POC at subsurface during $\mathrm{P} 2$ ) has ratios $\mathrm{P}: \mathrm{N}: \mathrm{C}$ which are near the classical Redfield ratios $(1: 16: 106)$, to within the uncertainties which are large for P1. The results for the contrasted labile (near-surface-subsurface) portion of the dissolved organic pool found for P1 (1:17:118) is also identical to the Redfield ratios within the very large uncertainties of more than $10 \%$ in these estimates. 

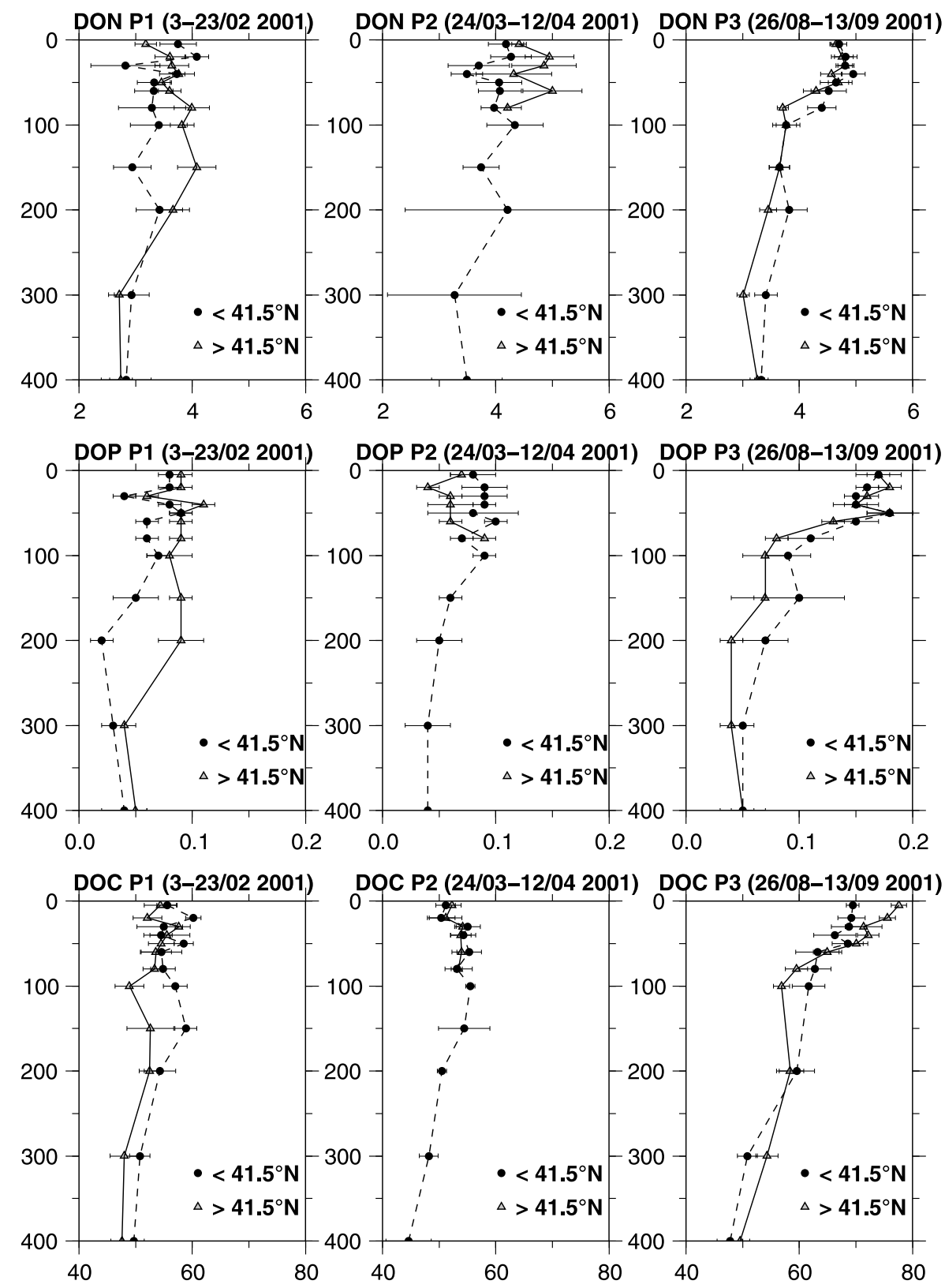

Figure A2. DON, DOP, and DOC for the surveys P1, P2, and P3. The averages are done separately for stations north and south of $41.7^{\circ} \mathrm{N}$ and error bars on the averages are indicated. 
[48] Acknowledgments. We are strongly indebted to the crew and the scientists on board the R/V Thalassa and Atalante for the collection of this large set of data with funding support by INSU for POMME. Our thanks go in particular to the chief scientists, Louis Prieur, J. C. Gascard, P. Mayzeaud, and Y. Desaubies. We are also very grateful for the meticulous work done by Françoise Besset at LOCEAN that made the data usable, as well as to the work by Louis Prieur and Caroline Pocho in identifying errors in bottle referencing. Special thanks to the Goddard Space Flight Center (NASA GSFC) for providing the SeaWiFS images used in this work. The authors are supported by CNRS with additional grants by INSU.

\section{References}

Blain, S., C. Guieu, H. Claustre, K. Leblanc, T. Moutin, B. Quéginer, J. Ras, and G. Sarthou (2005), Availability of iron for phytoplankton in the north-east Atlantic Ocean, Limnol. Oceanogr., 49, 2095-2104.

Bouruet-Aubertot, P., H. Mercier, F. Gaillard, and P. L'Herminier (2005), Evidence of strong inertia-gravity wave activity during the POMME experiment, J. Geophys. Res., 110, C07S06, doi:10.1029/2004JC002747.

Caniaux, G., S. Belamari, H. Giordani, A. Paci, and G. Reverdin (2005), A 1 year surface heat budget in the northeastern Atlantic basin during the POMME experiment: 2. Flux optimization, J. Geophys. Res., 110, C07S03, doi:10.1029/2004JC002695.

Claustre, H., M. Babin, D. Merien, J. Ras, L. Prieur, S. Dallot, O. Prasil, H. Dousova, and T. Moutin (2005), Toward a taxon-specific parameterization of bio-optical models of primary production: A case study in the North Atlantic, J. Geophys. Res., 110, C07S12, doi:10.1029/2004JC002634.

Fernández, C., I, P. Raimbault, G. Caniaux, N. Garcia, and P. Rimmelin (2005a), Influence of mesoscale eddies on nitrate distribution during the POMME program in the northeast Atlantic Ocean, J. Mar. Syst., 55, 155-175, doi:10.1016/j.jmarsys.2004.08.007.

Fernández, C., I, P. Raimbault, N. Garcia, P. Rimmelin, and G. Caniaux (2005b), An estimation of annual new production and carbon budgets in the northeast Atlantic Ocean during 2001, J. Geophys. Res., 110, C07S13, doi:10.1029/2004JC002616.

Gaillard, F., H. Mercier, and C. Kermabon (2005), A synthesis of the POMME physical data set: One year monitoring of the upper layer, J. Geophys. Res., 110, C07S07, doi:10.1029/2004JC002764.

Giordani, H., G. Caniaux, L. Prieur, A. Paci, and S. Giraud (2005), A 1 year mesoscale simulation of the northeast Atlantic: Mixed layer heat and mass budgets during the POMME experiment, J. Geophys. Res., 110, C07S08, doi:10.1029/2004JC002765.

González Dávila, M., J. M. Santana-Casiano, L. Merlivat, L. Barbero-Muñoz, and E. V. Dafner (2005), Fluxes of $\mathrm{CO}_{2}$ between the atmosphere and the ocean during the POMME project in the northeast Atlantic Ocean during 2001, J. Geophys. Res., 110, C07S11, doi:10.1029/2004JC002763.

Goutx, M., C. Guigue, N. Leblond, A. Desnues, A. Dufour, D. Aritio, and C. Guieu (2005), Particle flux in the northeast Atlantic Ocean during the POMME experiment (2001): Results from mass, carbon, nitrogen, and lipid biomarkers from the drifting sediment traps, J. Geophys. Res., 110, C07S20, doi:10.1029/2004JC002749.

Goyet, C., and S. D. Hacker (1992), Procedure for calibration of coulometric system used for total inorganic carbon measurements of seawater, Mar. Chem., 38, 37-51, doi:10.1016/0304-4203(92)90066-J.

Guieu, C., M. Roy-Barman, N. Leblond, C. Jeandel, M. Souhaut, B. Le Cann, A. Dufour, and C. Bournot (2005), Vertical particle flux in the northeast Atlantic Ocean (POMME experiment), J. Geophys. Res., 110, C07S18, doi:10.1029/2004JC002672.

Hopkinson, C. S., Jr., J. J. Vallino, and A. Nolin (2002), Decomposition of dissolved organic matter from the continental margin, Deep Sea Res. Part II, 49, 4461-4478, doi:10.1016/S0967-0645(02)00125-X.

Johnson, K. M., A. E. E. King, and J. M. Sieburth (1985), Coulometric $\mathrm{TCO}_{2}$ analyses for marine studies: An introduction, Mar. Chem., 16, 61-82, doi:10.1016/0304-4203(85)90028-3.

Koeve, W. (2001), Wintertime nutrients in the North Atlantic-New approaches and implications for new production estimates, Mar. Chem., 74, 245-260, doi:10.1016/S0304-4203(01)00016-0.

Körtzinger, A., K. Wolfgang, P. Kähler, and L. Mintrop (2001), C:N ratios in the mixed layer during the productive season in the northeast Atlantic
Ocean, Deep Sea Res. Part I, 48, 661-688, doi:10.1016/S09670637(00)00051-0.

Krémeur, A.-S., M. Lévy, O. Aumont, and G. Reverdin (2009), Impact of the subtropical mode water biogeochemical properties on primary production in the North Atlantic: New insights from an idealized model study, J. Geophys. Res., 114, C07019, doi:10.1029/2008JC005161.

Leblanc, K., A. Leynaert, C. Fernandez I, P. Rimmelin, T. Moutin, P. Raimbault, J. Ras, and B. Quéguiner (2005), A seasonal study of diatom dynamics in the North Atlantic during the POMME experiment (2001): Evidence for Si limitation of the spring bloom, J. Geophys. Res., 110, C07S14, doi:10.1029/2004JC002621.

Le Cann, B., M. Assenbaum, J.-C. Gascard, and G. Reverdin (2005), Observed mean and mesoscale upper ocean circulation in the midlatitude northeast Atlantic, J. Geophys. Res., 110, C07S05, doi:10.1029/ 2004JC002768

Lévy, M., Y. Lehahn, J.-M. André, L. Mémery, H. Loisel, and E. Heifetz (2005), Production regimes in the northeast Atlantic: A study based on Sea-viewing Wide Field-of-view Sensor (SeaWiFS) chlorophyll and ocean general circulation model mixed layer depth, J. Geophys. Res., 110, C07S10, doi:10.1029/2004JC002771.

Maixandeau, A., D. Lefèvre, H. Karayanni, U. Christaki, F. van Wambeke, M. Thyssen, C. Fernandez I, J. Uitz, K. Leblanc, and B. Quéginer (2005), Microbial community production, respiration, and structure of the microbial food web of an ecosystem in the northeastern Atlantic Ocean, J. Geophys. Res., 110, C07S17, doi:10.1029/2004JC002694.

Mémery, L., G. Reverdin, J. Paillet, and A. Oschlies (2005), Introduction to the POMME special section: Thermocline ventilation and biogeochemical tracer distribution in the northeast Atlantic Ocean and impact of mesoscale dynamics, J. Geophys. Res., 110, C07S01, doi:10.1029/ 2005JC002976.

Merlivat, L., M. Gonzalez Davila, G. Caniaux, J. Boutin, and G. Reverdin (2009), Mesoscale and diel monthly variability of $\mathrm{CO}_{2}$ and carbon fluxes at the ocean surface in the northeastern Atlantic, J. Geophys. Res., 114, C03010, doi:10.1029/2007JC004657.

Paillet, J., and H. Mercier (1997), An inverse model of the eastern North Atlantic general circulation and thermocline ventilation, Deep Sea Res. Part I, 44, 1293-1328, doi:10.1016/S0967-0637(97)00019-8.

Palter, J. B., M. S. Lozier, and R. T. Barber (2005), The effect of advection on the nutrient reservoir in the North Atlantic subtropical gyre, Nature, 437, 687-692, doi:10.1038/nature03969.

Raimbault, P., W. Pouvesle, F. Diaz, N. Garcia, and R. Sempéré (1999a), Wet-oxidation and automated colorimetry for simultaneous determination of organic carbon, nitrogen and phosphorus dissolved in seawater, Mar. Chem., 66, 161-169, doi:10.1016/S0304-4203(99)00038-9.

Raimbault, P., F. Diaz, W. Pouvesle, and B. Boudjellal (1999b), Simultaneous determination of particulate organic carbon, nitrogen and phosphorus collected on filters, using a semi-automatic wet-oxidation method, Mar. Ecol. Prog. Ser., 180, 289-295, doi:10.3354/meps180289.

Reverdin, G., M. Assenbaum, and L. Prieur (2005), Eastern North Atlantic mode waters during POMME (September 2000-2001), J. Geophys. Res., 110, C07S04, doi:10.1029/2004JC002613.

Sohrin, R., and R. Sempéré (2005), Seasonal variation in total organic carbon in the northeast Atlantic in 2000-2001, J. Geophys. Res., 110, C10S90, doi:10.1029/2004JC002731

Treguer, P., and P. Le Corre (1975), Manuel d'Analyses des Sels Nutritifs Dans l'Eau de Mer (Utilisation de l'Autoanalyseur II Technicon), 2nd ed., Lab. d'Oceanogr. Chim., Brest, France.

van Aken, H. M. (2001), The hydrography of the mid-latitude northeast Atlantic Ocean-Part III: The subducted thermocline water mass, Deep Sea Res. Part I, 48, 237-267, doi:10.1016/S0967-0637(00)00059-5.

D. Lefèvre and P. Raimbault, LMGEM, UMR 6117, COM, CNRS, 163 Avenue de Luminy, case 901, F-13288 Marseille CEDEX 09, France.

M. Lévy and G. Reverdin, LOCEAN, IPSL, UPMC, CNRS, case 100, 4 Place Jussieu, F-75252 Paris CEDEX 05, France. (gilles.reverdin@loceanipsl.upmc.fr) 